\title{
Clinical presentation, treatment and outcome of anaplastic thyroid carcinoma: results of a multicenter study in Germany
}

\author{
Julia Wendler ${ }^{1, *}$, Matthias Kroiss 1,*, Katja Gast², Michael C Kreiss|, \\ Stephanie Allelein ${ }^{4}$, Urs Lichtenauer ${ }^{5,+}$, Rainer Blaser ${ }^{6}$, Christine Spitzweg $^{2}$, \\ Martin Fassnacht ${ }^{7}$, Matthias Schott ${ }^{5}$, Dagmar Führer ${ }^{8}$ and Vera Tiedje ${ }^{8}$
}

'Department of Internal Medicine I, Division of Endocrinology and Diabetes, University of Würzburg, University Hospital Würzburg, Würzburg, Germany, ${ }^{2}$ Department of Internal Medicine II, University Hospital Munich, Ludwig-Maximilians-Universität Munich, München, Germany, ${ }^{3}$ Department of Nuclear Medicine, Central Hospital Augsburg, Augsburg, Germany, ${ }^{4}$ Division for Specific Endocrinology, University Hospital Düsseldorf, Düsseldorf, Germany, ${ }^{5}$ Department of Internal Medicine IV, University Hospital Munich, Ludwig-Maximilians-Universität München, München, Germany, ${ }^{6}$ Technical University Munich, Klinikum rechts der Isar, Institute for Medical Statistics and Epidemiology, München, Germany, ${ }^{7}$ University of Würzburg, Comprehensive Cancer Center, Würzburg, Germany, and ${ }^{8}$ Department of Endocrinology and Metabolism, University Hospital Essen, University Duisburg-Essen, Essen, Germany

*(J Wendler and M Kroiss contributed equally to this work)

${ }^{\dagger}$ (U Lichtenauer is now at Helios Kliniken Schwerin, Wismarsche Straße, Schwerin, Germany)

Correspondence should be addressed to $\mathrm{M}$ Kroiss or V Tiedje Email Kroiss_M@ukw.de or vera.tiedje@uk-essen.de

\begin{abstract}
Context: Anaplastic thyroid carcinoma (ATC) is an orphan disease and confers a dismal prognosis. Standard treatment is not established.

Objective: The aim of this study is to describe clinical characteristics, current treatment regimens and outcome of ATC and to identify clinical prognostic markers and treatment factors associated with improved prognosis.

Design: Retrospective cohort study at five German tertiary care centers.

Patients and methods: Totally 100 ATC patients diagnosed between 2000 and 2015 were included in the analysis. Diseasespecific overall survival (OS) was compared with the Kaplan-Meier method and log-rank test; Cox proportional hazard model was used to identify risk factors.

Results: The 6-month, 1-year and 5-year disease-specific OS rates were 37, 28 and 5\%, respectively. Stage-dependent OS at 6 months was 78, 54 and 18\% for stage IVA, B and C, respectively. 29\% patients survived >1 year. Multivariate analysis of OS identified age $\geq 70$ years, incomplete local resection status and the presence of distant metastasis as significant risk factors associated with shorter survival. Radical surgery (hazard ratio [HR] 2.20, 95\% confidence interval $(\mathrm{Cl}) 1.19-4.09, P=0.012)$, external beam radiation therapy (EBRT) $\geq 40 \mathrm{~Gy}(\mathrm{HR}=0.34,0.15-0.76, P=0.008)$ and any kind of chemotherapy (CTX) ( $\mathrm{HR}=11.64,2.42-60.39, P=0.003)$ were associated with longer survival in multivariate analyses adjusted for age and tumor stage. A multimodal treatment regimen was significantly associated with a survival benefit ( $\mathrm{HR}=1.04,1.01-1.08, P<0.0001)$ only in IVC patients.

Conclusion: Disease-specific OS is still poor in ATC. Treatment factors associated with improved OS provide a rationale to devise treatment pathways for routine care. Collaborative research structures should be aimed to advance treatment of ATC.

\section{Introduction}

Anaplastic thyroid carcinoma (ATC) is an orphan disease with an annual incidence of 1-2 per million.
Even though ATC accounts for less than $2 \%$ of all thyroid cancers, it is the cause of more than half of all thyroid 
cancer-associated deaths $(1,2,3)$. Unlike differentiated thyroid cancer (DTC), ATC confers a disease-specific mortality of nearly $100 \%$ (4).

Whereas in DTC, combination of surgery, adjuvant radioactive iodine ablation and TSH-suppressive therapy enable high rates of cure even in cases of extrathyroidal tumor manifestation, in ATC extensive disease precludes complete resection in many cases. In addition, lack of sodium iodine symporter (NIS) expression renders radioiodine treatment ineffective (4).

The clinical diagnosis of ATC is usually made upon a rapidly growing neck mass and symptoms caused by extension beyond the thyroid gland and invasion into neighboring organs such as trachea, esophagus and recurrent laryngeal nerve (5).

Multimodal therapy is usually advocated to prevent locoregional complications such as dyspnea, dysphagia and hemorrhage (6). However, most treatment options have low degrees of evidence and case series from single institutions are hampered by long study periods conferring significant bias. Prospective clinical trials are still scarce (7) and only one phase III clinical trial has been published but was prematurely discontinued due to slow recruitment (8).

Whereas in radioiodine refractory DTC tyrosine kinase inhibitors are established $(9,10)$, data are lacking in ATC and reported results of phase II clinical trials performed with sorafenib and pazopanib show limited efficacy $(11,12)$. Single case studies have exploited the presence of genetic driver alterations in ATC tumors to apply molecular targeted therapies $(13,14,15)$. Even with current treatments, median survival of ATC remains less than 6 months $(16,17)$ and there is an unmet need of improved treatment options.

Here, we set out to systematically collect 100 cases of ATC from five German tertiary referral centers in order to describe the clinical presentation and current treatment of ATC, to develop clinical prognostic markers and to identify treatments associated with more favorable prognosis.

\section{Patients and methods}

\section{Setting}

Data were retrieved from patients diagnosed with ATC between 2000 and 2015 in the following tertiary referral centers: Central Hospital Augsburg, University Hospital Düsseldorf, University Hospital Essen, University Hospital Munich and University Hospital Würzburg. The study protocol was approved by the ethics committee of the University of Würzburg (ID 96/13) and subsequently of all participating centers.

\section{Data acquisition}

Data on initial symptoms, diagnostic procedures, surgical interventions, histopathological findings and treatment modalities of ATC cases diagnosed between 2000 and 2015 at six German centers were retrieved by trained personnel at all sites through chart review using specifically designed report forms. The inclusion criteria were age $\geq 18$ years and evidence of ATC at histopathologic examination of the primary tumor (or lymph node or distant metastases in seven cases). Pathological reports were available in all but five cases. In those, histopathologic diagnosis was retrieved from other chart documents. The study endpoints were disease-related death or time interval from diagnosis to last follow-up alive. Disease stage was according to UICC (18).

\section{Statistical analysis}

Overall survival (OS) after ATC diagnosis was analyzed using Kaplan-Meier method and groups were compared using the log-rank test. For data with non-nominal distribution we used the Mann-Whitney U-test. Assessment of risk factors was performed by using the Cox proportional hazard regression model (forward and backward step-up regression). $P$ values $<0.05$ were considered statistically significant. Statistical analyses were performed with IBM SPSS Version 23.

\section{Results}

\section{Clinical characteristics}

Clinical characteristics of the 100 patients are provided in Table 1. Median follow-up was 5.7 months (range 0.03-162). Median age at initial diagnosis was 70.5 years (range 38-92). Seventy deaths due to ATC were observed and five patients died due to other causes. Median OS of the 70 disease-specific deaths was 172 days (range 1-3962). The 6-month, 1-year, 3-year and 5-year cause-specific survival (CSS) rates regardless of tumor stage were $35,26,18$ and $8 \%$, respectively. A total of 29 patients (16 males) achieved disease control exceeding 1 year after initial diagnosis. Mean age of these patients was 62.0 years (range 38-81). 
Table 1 Patient characteristics in ATC patients.

\begin{tabular}{|c|c|}
\hline Characteristic & No. of patients \\
\hline Number of patients & 100 \\
\hline \multicolumn{2}{|l|}{ Sex } \\
\hline Female & 52 \\
\hline Male & 48 \\
\hline \multicolumn{2}{|l|}{ Age at diagnosis (years) } \\
\hline Median (range) & $70.5(38-92)$ \\
\hline \multicolumn{2}{|l|}{ Tumor stage at initial diagnosis* } \\
\hline IVA & 9 \\
\hline IVB & 32 \\
\hline IVC & 54 \\
\hline Not reported & 5 \\
\hline \multicolumn{2}{|l|}{ Diameter of largest single tumor node (mm) } \\
\hline Median (range) & $60(12-160)$ \\
\hline Lymph node metastases at initial diagnosis & 55 \\
\hline Distant metastases at initial diagnosis & 54 \\
\hline Aerodigestive infiltration & 31 \\
\hline Esophagus & 6 \\
\hline Trachea & 18 \\
\hline Both & 7 \\
\hline Differentiated tumor part & 17 \\
\hline PTC & 12 \\
\hline FTC & 5 \\
\hline \multicolumn{2}{|l|}{ Symptoms at initial diagnosis } \\
\hline Local swelling/palpable nodule ${ }^{\ddagger}$ & 66 \\
\hline Hoarseness & 28 \\
\hline Dysphagia & 33 \\
\hline Dyspnea & 20 \\
\hline Others $^{\S}$ & 22 \\
\hline Unavailable & 27 \\
\hline
\end{tabular}

*UICC 7th edition 2009; " Lymph node or thyroid gland nodule; \$Weight loss, stridor, hypernatremia, symptoms of distant metastases.

\section{Symptoms at presentation and tumor stage}

Symptoms at primary diagnosis of ATC are shown in Table 1. In almost one-third of patients, information about initial symptoms were not available. Two-thirds of patients were diagnosed due to cervical mass either of the thyroid gland or related to cervical lymph node swelling. Other common complaints were dysphagia (33\%), hoarseness (28\%) and dyspnea (20\%) caused by compression or invasion of adjacent organs such as trachea, esophagus or recurrent laryngeal nerve. Previous thyroid disease included surgery for goiter in six, presence of benign thyroid nodules in three diseases and Hashimoto's thyroiditis in one patient before ATC diagnosis.

Disease was restricted to the thyroid gland (stage IVA) at diagnosis in only 9\% of cases. Almost 32\% had extrathyroidal infiltration (stage IVB), 55\% had cervical lymph node metastases and 54\% distant metastases (stage IVC). In 12\% metastatic disease was confirmed by biopsy and in $88 \%$ metastatic spread was diagnosed by imaging studies only. Location of distant metastases were lung $(n=51)$, mediastinum $(n=14)$ and bone $(n=15 \%)$. Rare cases showed metastatic spread in liver $(n=5)$, brain $(n=4)$, pleura $(n=3)$ and abdominal lymph nodes $(n=1)$.

\section{Treatment administered}

Complete thyroidectomy either as primary procedure or completion surgery of previous subtotal or hemithyroidectomy was performed in 51\% (Table 2). Complete local resection was achieved in only $14 \%$.

Surgery of metachronous cervical lymph node metastases was performed in three patients, of pulmonary

Table 2 Therapeutic characteristics in ATC patients.

\begin{tabular}{l} 
Therapeutic regimen \\
\hline Primary surgery \\
Thyroidectomy \\
Hemithyroidectomy \\
Two-stage thyroidectomy \\
Completion of previous \\
Thyroid surgery \\
Tumor reduction \\
Explorative surgery \\
No surgery \\
Resection status \\
Local R0 \\
Local R1 \\
Local R2 \\
Local Rx \\
External beam radiation \\
Adjuvant \\
Local palliative \\
Distant metastases* \\
Palliative treatment \\
Dose (Gy) \\
Median (range) \\
Chemotherapy \\
Doxorubicin weekly \\
Paclitaxel weekly \\
Paclitaxel + pemetrexed \\
Doxorubicin + cisplatin \\
Carboplatin + paclitaxel \\
Tyrosine kinase inhibitors \\
Other \\
Multimodal approaches \\
Surgery. CTX and EBRT ${ }^{\S}$ \\
Surgery and EBRT \\
Only surgery \\
Only radiation \\
Radiation + CTX \\
Surgery+CTX \\
Chemotherapy only \\
Best supportive care \\
\hline \\
\hline
\end{tabular}

\begin{tabular}{cc}
\hline No. \\
\hline 83 \\
43 \\
19 \\
8 \\
6 \\
\\
3 \\
4 \\
17 \\
14 \\
27 \\
52 \\
6 \\
81 \\
32 \\
49 \\
11 \\
\\
\\
$57.6(13.5-80)$ \\
56 \\
25 \\
9 \\
8 \\
8 \\
14 \\
10 \\
10 \\
49 \\
19 \\
11 \\
9 \\
4 \\
4 \\
0 \\
4 \\
\end{tabular}

*All patients who received EBRT of metastases also received EBRT to the neck; ${ }^{\ddagger}$ More than one regimen in 18 patients; ${ }^{\S} \mathrm{CTX}$, chemotherapy; EBRT, external beam radiation therapy. 
metastases in two cases and pleurectomy was performed for treatment of pleural metastases in a single case.

Almost $56 \%$ of all ATC patients received chemotherapy (CTX, Table 2). Common cytotoxic drugs were doxorubicin, paclitaxel, pemetrexed and platinumcontaining regimens. About $10 \%$ of patients underwent targeted therapies with pazopanib $(n=4)$, sorafenib $(n=4)$, erlotinib $(n=1)$ and vemurafenib $(n=1$, administered in a case with evidence of BRAF V600E mutation). Almost 18 patients received more than one chemotherapeutic regimen after progression of disease.

About $81 \%$ of ATC patients received external beam radiation therapy (EBRT; $32 \%$ as adjuvant, $49 \%$ as palliative treatment). Median overall dose was $57.6 \mathrm{~Gy}$ (range 13.5-80 Gy). Eleven of the forty-nine patients with palliative external beam radiation therapy (EBRT) had EBRT of metastases (bone, $n=6$; brain, $n=3$; mediastinum, $n=2$ ) in addition to local EBRT. Two patients received a second series of EBRT to the neck due to local recurrence.

Only $49 \%$ of patients received a multimodal therapeutic approach defined as surgery, and sequential or simultaneous external beam radiation and chemotherapy.

About $17 \%$ of patients underwent tracheotomy and $11 \%$ percutaneous endoscopic gastrostomy during the course of the disease for palliation of local tumor complications or side effects of local EBRT.

\section{Tumor stage-dependent OS}

The UICC stage-dependent survival is shown in Fig. 1. Stage-dependent median OS was 26, 11 and 3 months for stage IVA, IVB and IVC, respectively $(P<0.0001$ by log-rank). The 6-month and 1-year CSS were 78 and $66 \%$ (IVA), 54 and 39\% (IVB), and 18 and 13\% (IVC) $(P<0.0001$ by log-rank).

\section{Pre-therapeutic factors of prognosis}

Patient- and tumor-related factors were assessed for prognostic relevance with OS and 6-month and 1-year survival rates as endpoints (Table 3 ). Univariate analysis using Cox proportional hazard modeling revealed the following factors to be significantly associated with improved outcome: age $<70$ years, absence of metastases (lymph node and distant), absence of aerodigestive infiltration and complete local tumor resection. After multivariable adjustment statistical significance was retained for age $<70$ years, presence of distant metastases and complete local tumor resection.

\section{Treatment-related factors of prognosis}

After multivariable adjustment for age and tumor stage, radical surgery $(\mathrm{HR}=2.201,1.186-4.086, \quad P=0.012)$, EBRT $(\mathrm{HR}=0.339,0.152-0.759, P=0.008)$, any kind of CTX $(\mathrm{HR}=11.636,2.242-60.394, P=0.003)$, and - most importantly - a multimodal therapeutic regimen of combined surgery, EBRT and chemotherapy $(\mathrm{HR}=0.050$, 0.009-0.276) were significantly associated with improved OS (Fig. 2A).

To explore the impact of different chemotherapies on survival, we focused on those patients who received surgery, EBRT and chemotherapy and found treatment with combined paclitaxel and pemetrexed to be associated with statistically significant likelihood of longer OS compared with other chemotherapeutic regimens $(P<0.001$, Mann-Whitney $U$-test, Table 4$)$.

\section{Stage-dependent treatment outcome}

In order to gain insight into the impact of treatment in a stage-specific manner, we analyzed treatment-related disease-specific OS separately for each stage (Table 5). The low number of patients precluded this type of analysis in stage IVA.

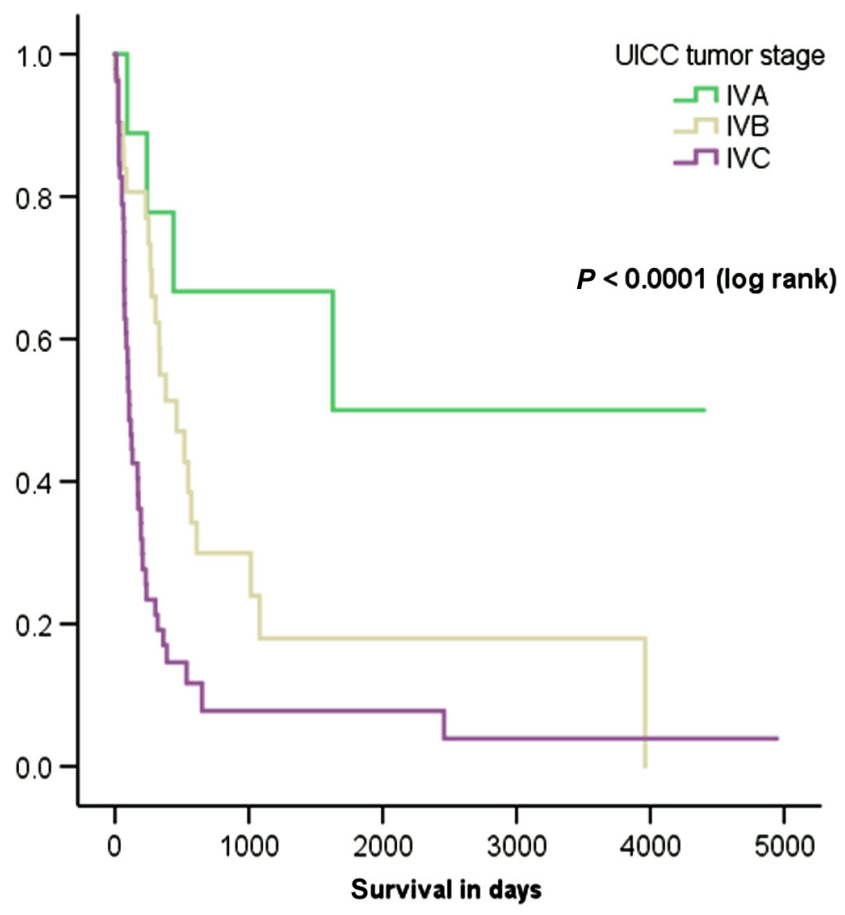

Figure 1

Kaplan-Meier analyses of overall survival by tumor stage: IVA $(n=7)$, IVB $(n=29)$, IVC $(n=47)$. Log-rank test $P<0.0001$. 
Univariate analysis demonstrated a significantly longer survival for EBRT $\geq 40$ Gy compared with $<40$ Gy in stage IVB patients $(P=0.017)$ and any kind of CTX versus no CTX and EBRT $\geq 40 \mathrm{~Gy}$ vs $<40 \mathrm{~Gy}$ in stage IVC patients $(P<0.0001$ and $P=0.004)$. Combination of treatment modalities such as surgery, EBRT and CTX was associated with more favorable outcome in IVC patients $(P=0.012)$.

After multivariate adjustment for age, in IVB patients external beam radiation $\geq 40 \mathrm{~Gy}$ (HR $=0.109,0.019-0.631$, $P=0.013)$ and in IVC patients CTX (HR $=0.231$, 0.083-0.641, $\quad P=0.005$ ) remained associated with significantly longer OS.
In stages IVA and IVB, all patients received additional treatment beyond surgery.

Combination of surgery with either CTX or EBRT versus surgery combined with CTX and EBRT showed no statistically significant association with OS in stage IVA OS $(\mathrm{HR}=1.589,0.159-15.930)$ and stage IVB $(\mathrm{HR}=0.772$, 0.267-2.234). At variance, a multimodal therapeutic regimen combining radical surgery with sequential or simultaneous CTX and EBRT showed a survival benefit in IVC patients (HR=0.1, 0.03-0.31, $P<0.0001)$. Surgery combined with either CTX or EBRT alone had no statistically significant benefit compared with surgery alone in stage IVC (HR=0.490, 0.02-1.44) (Fig. 2B).

Table 3 Prognostic factors in ATC patients. Bold values indicate statistical significance $P<0.05$.

\begin{tabular}{|c|c|c|c|c|c|c|c|}
\hline \multirow[b]{2}{*}{ Prognostic factors } & \multicolumn{4}{|c|}{ Univariate analyses } & \multicolumn{3}{|c|}{ Multivariate analyses } \\
\hline & $\begin{array}{c}\text { Median } \\
\text { survival } \\
\text { (days) }\end{array}$ & $\begin{array}{c}\text { 6-month } \\
\text { survival rate } \\
(\%)\end{array}$ & $\begin{array}{c}\text { 1-year } \\
\text { survival rate } \\
(\%)\end{array}$ & $\begin{array}{c}P \\
\text { (log rank) }\end{array}$ & $\mathrm{HR}$ & $95 \% \mathrm{Cl}$ & $\begin{array}{c}P \\
\text { (cox regression) }\end{array}$ \\
\hline \multicolumn{8}{|l|}{ Pretreatment factors } \\
\hline \multicolumn{8}{|l|}{ Sex } \\
\hline Male $(n=48)$ & 207 & 37 & 27 & 0.132 & & & \\
\hline Female $(n=52)$ & 251 & 32 & 25 & & & & \\
\hline \multicolumn{8}{|c|}{ Age at initial diagnosis (years) } \\
\hline$<70(n=46)$ & 340 & 60 & 33 & $<0.0001$ & & & \\
\hline$\geq 70(n=54)$ & 140 & 69 & 29 & & 1.048 & $1.015-1.082$ & 0.004 \\
\hline \multicolumn{8}{|l|}{ T status } \\
\hline $4 a(n=11)$ & 458 & 56 & 44 & 0.064 & & & \\
\hline $4 \mathrm{~b}(n=79)$ & 192 & 27 & 21 & & & & \\
\hline \multicolumn{8}{|l|}{$\mathrm{N}$ status } \\
\hline No $(n=24)$ & 537 & 65 & 49 & 0.001 & & & \\
\hline $\mathrm{N} 1(n=55)$ & 178 & 24 & 17 & & 1.601 & $0.759-4.068$ & 0.217 \\
\hline \multicolumn{8}{|l|}{ M status } \\
\hline $\mathrm{MO}(n=40)$ & 519 & 61 & 48 & $<0.0001$ & & & \\
\hline $\mathrm{M} 1(n=55)$ & 148 & 17 & 12 & & 2.718 & $1.384-5.342$ & 0.004 \\
\hline \multicolumn{8}{|l|}{ Aerodigestive infiltration } \\
\hline No $(n=67)$ & 304 & 42 & 33 & 0.005 & & & \\
\hline Yes $(n=31)$ & 140 & 23 & 15 & & 1.915 & $0.901-4.068$ & 0.091 \\
\hline \multicolumn{8}{|l|}{ Complete local resection } \\
\hline Yes $(n=14)$ & 1098 & 71 & 71 & 0.001 & & & \\
\hline No $(n=79)$ & 180 & 30 & 20 & & 5.539 & $1.858-16.514$ & 0.002 \\
\hline \multicolumn{8}{|l|}{ DTC tumor part } \\
\hline No $(n=78)$ & 197 & 32 & 28 & 0.179 & & & \\
\hline Yes $(n=17)$ & 395 & 55 & 24 & & & & \\
\hline \multicolumn{8}{|l|}{ Treatment factors* } \\
\hline \multicolumn{8}{|l|}{ Thyroid surgery } \\
\hline Radical $(n=51)$ & 264 & 33 & 28 & 0.376 & & & \\
\hline Other or none $(n=49)$ & 169 & 37 & 25 & & 2.201 & $1.186-4.086$ & 0.012 \\
\hline \multicolumn{8}{|l|}{ External beam radiation } \\
\hline$\geq 40$ Gy $(n=61)$ & 366 & 50 & 38 & $<0.0001$ & & & \\
\hline$<40 \mathrm{~Gy}(n=14)$ & 124 & 9 & 0 & & 0.339 & $0.152-0.759$ & 0.008 \\
\hline \multicolumn{8}{|l|}{ Chemotherapy } \\
\hline No $(n=44)$ & 131 & 21 & 17 & 0.003 & & & \\
\hline Yes $(n=56)$ & 338 & 45 & 33 & & 11.636 & $2.424-60.394$ & 0.003 \\
\hline
\end{tabular}


A

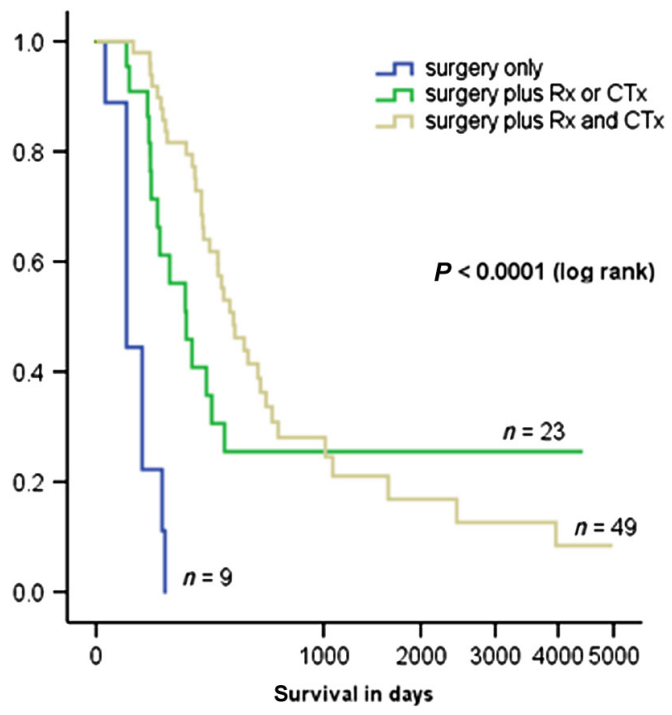

B

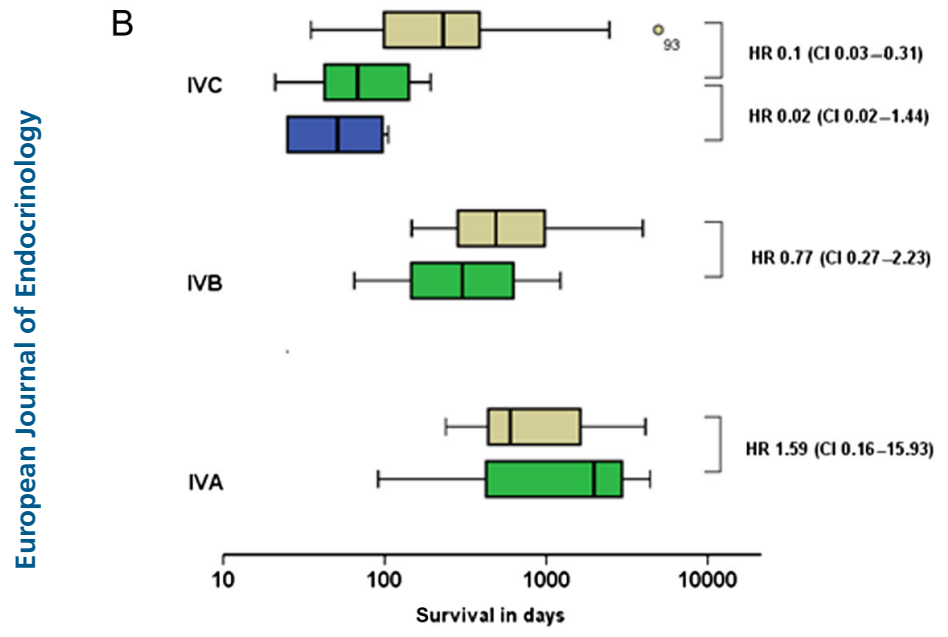

surgery onty $\square$ surgery phus Rx or CIX $\square$ surgery plus $R \times$ and CIX

\section{Figure 2}

(A) Kaplan-Meier curve: therapy-dependent survival. Log-rank test $(P<0.0001)$; (B) box plots: survival analyses by tumor stage according to treatment.

\section{Discussion}

Despite an increasing number of publications over the past ten years, the available evidence is still limited to estimate prognosis and to provide evidence for optimal treatment of ATC. Sugitani et al. collected the largest ATC cohort yet published including 677 patients (19). The second largest study by Kebebew et al. (2) reported on 516 ATC patients of the U.S. National Cancer Institute's Surveillance, Epidemiology and End Results diagnosed between 1973 and 2000.
Table 4 Survival-dependent administered chemotherapeutic regimen.

\begin{tabular}{|c|c|c|}
\hline Chemotherapeutic drug* & $\begin{array}{l}\text { Survival } \\
\text { (days) }\end{array}$ & $\begin{array}{c}P \text { (Mann-Whitney } \\
\text { U-test) }\end{array}$ \\
\hline \multicolumn{3}{|l|}{ Doxorubicin weekly } \\
\hline Yes $(n=20)$ & 316.5 & 0.784 \\
\hline No $(n=29)$ & 380 & \\
\hline \multicolumn{3}{|l|}{ Paclitaxel weekly } \\
\hline Yes $(n=9)$ & 239 & 0.869 \\
\hline No $(n=40)$ & 345.5 & \\
\hline Paclitaxel and pemetrexed & & 0.001 \\
\hline Yes $(n=9)$ & 651 & \\
\hline No $(n=40)$ & 252 & \\
\hline Paclitaxel and carboplatin & & 0.610 \\
\hline Yes $(n=13)$ & 438 & \\
\hline No $(n=36)$ & 316.5 & \\
\hline Doxorubicin+ cisplatin & & 0.165 \\
\hline Yes $(n=7)$ & 235 & \\
\hline No $(n=42)$ & 383.5 & \\
\hline TKI & & 0.113 \\
\hline Yes $(n=9)$ & 519 & \\
\hline No $(n=40)$ & 238.5 & \\
\hline
\end{tabular}

Bold values indicate statistical significance $P<0.05$.

*Analyses only contain the 49 patients who received multimodal

treatment including surgery, external beam radiation and chemotherapy; TKI, tyrosine kinase inhibitor.

In the present study, we included data of 100 patients with ATC diagnosed between 2000 and 2015 at five German tertiary referral centers. In comparison with the studies mentioned above, our case collection has the advantage that source data of ATC were retrieved from the case records using specifically designed report forms and trained personnel. In addition, our study is likely to more closely mirror contemporary treatment practice given the more recent time frame of the study. However, our study suffers from its retrospective nature and referral bias since only tertiary care centers were included.

In this cohort, OS and 1-year survival rates were similar to data reported earlier. Median OS and 1-year survival rates were 26 months and $66 \%$ in stage IVA, 11 months and 39\% in IVB and 3 months and 13\% in IVC. In comparison with the cohorts of Sugitani or Ito et al., this cohort contains a larger proportion of IVC patients (Sugitani et al.: IVA 13\%, IVB 44\%, IVC 12\%; Ito et al.: IVA 0\%, IVB 62.5\%, IVC 37.5\%; this cohort IVC 54\%) The reason for this difference may be related to referral bias given that only tertiary care centers participated in this study.

By applying multivariate analysis, we found age $\geq 70$ years, presence of distant metastases and incomplete local tumor resection to be independent risk factors of unfavorable outcome. 
Table 5 Stage-dependent treatment and multimodality of therapy in ATC patients.

\begin{tabular}{|c|c|c|c|c|c|c|c|}
\hline \multirow[b]{2}{*}{ Treatment } & \multicolumn{4}{|c|}{ Univariate analyses } & \multicolumn{3}{|c|}{ Cox proportional hazards model } \\
\hline & $\begin{array}{l}\text { Median survival } \\
\text { (days) }\end{array}$ & $\begin{array}{c}\text { 6-month survival } \\
\text { rate }(\%)\end{array}$ & $\begin{array}{c}\text { 1-year survival } \\
\text { rate }(\%)\end{array}$ & Log rank $P$ & $\mathrm{HR}$ & $95 \% \mathrm{Cl}$ & $P$ value \\
\hline \multicolumn{8}{|l|}{ Stage IVA } \\
\hline \multicolumn{8}{|l|}{ Surgery } \\
\hline Radical $(n=6)$ & 526 & 67 & 48 & 0.356 & & & \\
\hline Other or none $(n=3)$ & 1098 & 100 & 100 & & & & \\
\hline \multicolumn{8}{|l|}{ External beam radiation } \\
\hline$\geq 40 \mathrm{~Gy}(n=8)$ & 1098 & 71 & 54 & 0.093 & & & \\
\hline$<40 \mathrm{~Gy}(n=0)$ & - & - & - & & & & \\
\hline \multicolumn{8}{|l|}{ Chemotherapy } \\
\hline No $(n=3)$ & 1098 & 67 & 67 & 0.601 & & & \\
\hline Yes $(n=6)$ & 1098 & 80 & 57 & & & & \\
\hline \multicolumn{8}{|l|}{ Stage IVB } \\
\hline \multicolumn{8}{|l|}{ Surgery } \\
\hline Radical $(n=16)$ & 529 & 57 & 49 & 0.349 & & & \\
\hline Other or none $(n=16)$ & 478 & 62 & 43 & & & & \\
\hline \multicolumn{8}{|l|}{ External beam radiation } \\
\hline$\geq 40$ Gy $(n=24)$ & 604 & 26 & 20 & 0.017 & & & \\
\hline$<40 \mathrm{~Gy}(n=2)$ & 183 & 0 & 0 & & 0.109 & $0.019-0.631$ & 0.013 \\
\hline \multicolumn{8}{|l|}{ Chemotherapy } \\
\hline No $(n=13)$ & 381 & 51 & 38 & 0571 & & & \\
\hline Yes $(n=19)$ & 548 & 63 & 50 & & & & \\
\hline \multicolumn{8}{|l|}{ Stage IVC } \\
\hline \multicolumn{8}{|l|}{ Surgery } \\
\hline Radical $(n=27)$ & 155 & 9 & 9 & 0.661 & & & \\
\hline Other or none $(n=27)$ & 137 & 22 & 10 & & & & \\
\hline \multicolumn{8}{|l|}{ External beam radiation } \\
\hline$\geq 40$ Gy $(n=27)$ & 257 & 71 & 56 & 0.004 & & & \\
\hline$<40 \mathrm{~Gy}(n=12)$ & 117 & 50 & 0 & & 0.549 & $0.211-1.432$ & 0.220 \\
\hline \multicolumn{8}{|l|}{ Chemotherapy } \\
\hline No $(n=26)$ & 100 & 0 & 0 & $<0.0001$ & & & \\
\hline Yes $(n=28)$ & 258 & 28 & 18 & & 0.231 & $0.083-0.641$ & 0.005 \\
\hline
\end{tabular}

Bold values indicate statistical significance $P<0.05$.

This is in accordance with the data by Sugitani et al. (19) who found age $\geq 70$ years, presence of acute symptoms and leukocytosis at initial diagnosis, T4b tumor, diameter of tumor size $>5 \mathrm{~cm}$ and distant metastasis to be independent predictors of poor OS, which is in line with previous results (20). The study from the National Cancer Institute (2) concluded that age $<60$ years, intrathyroidal tumor mass and surgery combined with radiotherapy are independent favorable prognostic factors of disease-specific mortality that is similar to smaller cohorts $(21,22)$.

Given that the therapeutic management of ATC has not been firmly established, we queried our data for treatments associated with improved prognosis.

Surprisingly, complete thyroidectomy was not significantly correlated with longer OS in univariate analyses. As previous studies $(2,19)$ strongly suggested a beneficial effect, we adjusted for tumor stage and age and confirmed a significant association of complete surgery with improved outcome. Of note, microscopically complete local resection was achieved in only $17.6 \%$ of patients in our cohort. This is at variance to other cohorts where complete local resection rates of 30\% (23) and $31 \%$ (9 out of 29) were reported (24). However, it has been stated earlier (25) that the significance of complete thyroidectomy remains a matter of controversy due to the majority of unresectable tumors at initial diagnosis and the important morbidity related to aggressive local resection (26).

It is a remarkable characteristic of our study, that unlike in the studies by Ito et al. (25) and Sugitani et al. (19), $80 \%$ of patients received chemotherapy and/or external beam radiation in addition to surgery with no single patient receiving surgery only in stage IVA and IVB patients. About $49 \%$ of all patients received a multimodal treatment combining three modalities. At variance, in previous studies a multimodal approach was applied in $16 \%$ in stage IVA (19), 15\% (19) and 24\% (25), respectively, 
in stage IVB and 0\% (25) (not reported by Sugitani et al.) in stage IVC.

This may relate to referral bias but also might reflect the fact that in the centers contributing to this study and within the pre-defined timescale, aggressive surgical treatment has partly ceded place to other treatment modalities. Along these lines, data from the entire cohort suggest a treatment benefit from external beam radiation and chemotherapy after adjustment for stage and age.

Considering only patients who received multimodal treatment, not all chemotherapy regimens showed association with improved survival to the same extent. Doxorubicin plus cisplatin was significantly associated with a less favorable prognosis, potentially due to the significant hematologic toxicity. At variance, combined paclitaxel and pemetrexed showed statistically significant association with improved OS in comparison with other regimens. These data have to be interpreted with caution, because only 51 patients received chemotherapy in a multimodal approach with only 8 (paclitaxel + pemetrexed) to 18 (doxorubicin) patients receiving the same regimen.

In a stage-dependent perspective, the low number of patients in stage IVA did not permit statistically significant associations with treatment to be found. In IVB patients we observed a trend toward longer OS with multimodal treatment, which, however, missed statistical significance. This is similar to the data published by Sugitani et al. (19) and Higashiyama et al. (27); hence, providing a rationale to administer high-dose EBRT and chemotherapies in these cases.

More clearly, in patients with stage IVC, treatment with combined radical surgery, EBRT and CTX was associated with significantly longer OS. However, median OS in the multimodal treatment group was still poor with a median of 330 vs 68 days. It must be stated, that this result may in part be attributable to selection bias. It is conceivable that only patients in good general health received multimodal therapy including radical surgery, external beam radiation and chemotherapy. In the group of patients initially diagnosed at age $\leq 60$ years, $76.9 \%$ received multimodal treatment compared with $16.7 \%$ in patients aged $\geq 80$ years of patients. Of note, the retrospective nature of our study precludes conclusions regarding quality of life in all groups, which, however, is of paramount importance in this dismal disease. Further, tumors in this study have not been characterized at the molecular level and hence we cannot offer molecular markers of treatment response.

This multicenter analysis illustrates the heterogeneous treatment approaches applied in ATC patients in
Germany, due to lack of established therapies and the rare and aggressive nature of the disease. To unify and subsequently improve ATC patient treatment in Germany, a therapy protocol was developed by representatives involved in ATC care (endocrine surgery, pathology, endocrinology, radiotherapy and medical oncology). This protocol involves surgery in selected cases, followed by combined EBRT and chemotherapy and mutational screening of known oncogenes with subsequent targeted therapy (28). Importantly, we suggest that all patients should have access to specialized palliative care early in the course of the disease.

In conclusion, this study confirms previous reports implicating age, which may be regarded as a surrogate marker of general performance, and tumor stage as the key factors. For stage IVB and IVC at least, a comprehensive and aggressive multimodal approach including high-dose EBRT and chemotherapy is the current treatment of choice. Whereas none of the retrospective studies published so far was able to recommend for or against a particular combination of cytotoxic chemotherapy, we found a highly significant association of paclitaxel plus pemetrexed with improved outcome, although numbers are small. Owing to the limitations of retrospective analyses, there is a strong argument in favor of a prospective international clinical trial to determine the most favorable chemotherapeutic regimen.

However, given the overall poor outcome of current treatment, it is recommended to include patients into early clinical trials or administer targeted therapies on a compassionate use basis whenever a plausible molecular target can be identified $(14,15,29)$.

In the absence of a molecular targeted clinical trial, development of consensus treatment pathways such as the one described above constitute a way to characterize predictors of treatment response and to improve current treatment concepts.

\section{Declaration of interest}

The authors declare that there is no conflict of interest that could be perceived as prejudicing the impartiality of the research reported.

\section{Funding}

This study was supported, in part, by a postgraduate training grant of the Comprehensive Cancer Center Mainfranken to M K.

\section{Acknowledgements}

The authors thank all patients, their families and caregivers for providing clinical data for this study. 


\section{References}

1 Are C \& Shaha AR. Anaplastic thyroid carcinoma: biology, pathogenesis, prognostic factors, and treatment approaches. Annals of Surgical Oncology 200613 453-464. (doi:10.1245/ASO.2006.05.042)

2 Kebebew E, Greenspan FS, Clark OH, Woeber KA \& McMillan A. Anaplastic thyroid carcinoma. Treatment outcome and prognostic factors. Cancer 2005103 1330-1335. (doi:10.1002/cncr.20936)

3 Sherman SI. Thyroid carcinoma. Lancet 2003361 501-511. (doi:10.1016/S0140-6736(03)12488-9)

4 Untch BR \& Olson JA. Anaplastic thyroid carcinoma, thyroid lymphoma, and metastasis to thyroid. Surgical Oncology Clinics of North America 200615 661-679. (doi:10.1016/j.soc.2006.05.006)

5 Neff RL, Farrar WB, Kloos RT \& Burman KD. Anaplastic thyroid cancer. Endocrinology Metabolism Clinics of North America 200837 525-538. (doi:10.1016/j.ecl.2008.02.003)

6 Smallridge RC, Ain KB, Asa SL, Bible KC, Brierley JD, Burman KD, Kebebew E, Lee NY, Nikiforov YE, Rosenthal MS, et al. American Thyroid Association guidelines for management of patients with anaplastic thyroid cancer. Thyroid 201222 1104-1139. (doi:10.1089/ thy.2012.0302)

7 Kojic SL, Strugnell SS \& Wiseman SM. Anaplastic thyroid cancer: a comprehensive review of novel therapy. Expert Review of Anticancer Therapy 201111 387-402. (doi:10.1586/era.10.179)

8 Sosa JA, Elisei R, Jarzab B, Balkissoon J, Lu SP, Bal C, Marur S, Gramza A, Yosef RB, Gitlitz B, et al. Randomized safety and efficacy study of fosbretabulin with paclitaxel/carboplatin against anaplastic thyroid carcinoma. Thyroid 201424 232-240. (doi:10.1089/ thy.2013.0078)

9 Brose MS, Nutting CM, Jarzab B, Elisei R, Siena S, Bastholt L, de la Fouchardiere C, Pacini F, Paschke R, Shong YK, et al. Sorafenib in radioactive iodine-refractory, locally advanced or metastatic differentiated thyroid cancer: a randomised, doubleblind, phase 3 trial. Lancet 2014384 319-328. (doi:10.1016/S01406736(14)60421-9)

10 Schlumberger M, Tahara M, Wirth LJ, Robinson B, Brose MS, Elisei R, Habra MA, Newbold K, Shah MH, Hoff AO, et al. Lenvatinib versus placebo in radioiodine-refractory thyroid cancer. New England Journal of Medicine 2015372 621-630. (doi:10.1056/NEJMoa1406470)

11 Savvides P, Nagaiah G, Lavertu P, Fu P, Wright JJ, Chapman R, Wasman J, Dowlati A \& Remick SC. Phase II trial of sorafenib in patients with advanced anaplastic carcinoma of the thyroid. Thyroid 201323 600-604. (doi:10.1089/thy.2012.0103)

12 Bible KC, Suman VJ, Menefee ME, Smallridge RC, Molina JR, Maples WJ, Karlin NJ, Traynor AM, Kumar P, Goh BC, et al. A multiinstitutional phase 2 trial of pazopanib monotherapy in advanced anaplastic thyroid cancer. Journal of Clinical Endocrinology and Metabolism 201297 3179-3184. (doi:10.1210/jc.2012-1520)

13 Godbert Y, Henriques de Figueiredo B, Bonichon F, Chibon F, Hostein I, Perot G, Dupin C, Daubech A, Belleannee G, Gros A, et al. Remarkable response to crizotinib in woman with anaplastic lymphoma kinase-rearranged anaplastic thyroid carcinoma. Journal of Clinical Oncology 201533 e84-e87. (doi:10.1200/JCO.2013.49.6596)

14 Rosove MH, Peddi PF \& Glaspy JA. BRAF V600E inhibition in anaplastic thyroid cancer. New England Journal of Medicine $2013 \mathbf{3 6 8}$ 684-685. (doi:10.1056/NEJMc1215697)

15 Wagle N, Grabiner BC, Van Allen EM, Amin-Mansour A, Taylor-Weiner A, Rosenberg M, Gray N, Barletta JA, Guo Y,
Swanson SJ, et al. Response and acquired resistance to everolimus in anaplastic thyroid cancer. New England Journal of Medicine 2014 371 1426-1433. (doi:10.1056/NEJMoa1403352)

16 Smallridge RC \& Copland JA. Anaplastic thyroid carcinoma: pathogenesis and emerging therapies. Clinical Oncology 201022 486-497. (doi:10.1016/j.clon.2010.03.013)

17 Kebebew E. Anaplastic thyroid cancer: rare, fatal, and neglected. Surgery 2012152 1088-1089. (doi:10.1016/j.surg.2012.08.059)

18 Edge SB, Byrd DR, Carducci MA, Compton CC, Fritz AG, Greene F $\&$ Trotti A. American Joint Committee on Cancer (AJCC) (2009) Cancer Staging Manual, 7th ed. New York, NY, USA: Springer, 2009.

19 Sugitani I, Miyauchi A, Sugino K, Okamoto T, Yoshida A \& Suzuki S. Prognostic factors and treatment outcomes for anaplastic thyroid carcinoma: ATC Research Consortium of Japan cohort study of 677 patients. World Journal of Surgery 201236 1247-1254. (doi:10.1007/ s00268-012-1437-z)

20 Sugino K, Ito K, Mimura T, Nagahama M, Fukunari N, Kubo A \& Iwasaki $\mathrm{H}$. The important role of operations in the management of anaplastic thyroid carcinoma. Surgery 2002131 245-248. (doi:10.1067/msy.2002.119936)

21 Besic N, Hocevar M, Zgajnar J, Pogacnik A, Grazio-Frkovic S \& Auersperg M. Prognostic factors in anaplastic carcinoma of the thyroid-a multivariate survival analysis of 188 patients. Langenbeck's Archives of Surgery 2005390 203-208. (doi:10.1007/s00423-004-0524-5)

22 Kim TY, Kim KW, Jung TS, Kim JM, Kim SW, Chung KW, Kim EY, Gong G, Oh YL, Cho SY, et al. Prognostic factors for Korean patients with anaplastic thyroid carcinoma. Head and Neck 200729 765-772. (doi:10.1002/hed.20578)

23 McIver B, Hay ID, Giuffrida DF, Dvorak CE, Grant CS, Thompson GB, van Heerden JA \& Goellner JR. Anaplastic thyroid carcinoma: a 50-year experience at a single institution. Surgery $2001 \mathbf{1 3 0}$ 1028-1034. (doi:10.1067/msy.2001.118266)

24 Brignardello E, Palestini N, Felicetti F, Castiglione A, Piovesan A, Gallo M, Freddi M, Ricardi U, Gasparri G, Ciccone G, et al. Early surgery and survival of patients with anaplastic thyroid carcinoma: analysis of a case series referred to a single institution between 1999 and 2012. Thyroid 201424 1600-1606. (doi:10.1089/thy.2014.0004)

25 Ito K, Hanamura T, Murayama K, Okada T, Watanabe T, Harada M, Ito T, Koyama H, Kanai T, Maeno K, et al. Multimodality therapeutic outcomes in anaplastic thyroid carcinoma: improved survival in subgroups of patients with localized primary tumors. Head and Neck 201234 230-237. (doi:10.1002/hed.21721)

26 Passler C, Scheuba C, Prager G, Kaserer K, Flores JA, Vierhapper H \& Niederle B. Anaplastic (undifferentiated) thyroid carcinoma (ATC). A retrospective analysis. Langenbeck's Archives of Surgery 1999384 284-293. (doi:10.1007/s004230050205)

27 Higashiyama T, Ito Y, Hirokawa M, Fukushima M, Uruno T, Miya A, Matsuzuka F \& Miyauchi A. Induction chemotherapy with weekly paclitaxel administration for anaplastic thyroid carcinoma. Thyroid 201020 7-14. (doi:10.1089/thy.2009.0115)

28 Tiedje V, Kroiss M, Dralle H, Ting S, Stuschke M, Flentje M, Bauer S, Weber F, Brabant G, Lorenz K, et al. Protokoll zur multimodalen Therapie des anaplastischen Schilddrüsenkarzinoms. Endokrinologie Informationen 201539 63-65.

29 Godbert Y, Henriques de Figueiredo B, Bonichon F, Chibon F, Hostein I, Perot G, Dupin C, Daubech A, Belleannee G, Gros A, et al. Remarkable response to crizotinib in woman with anaplastic lymphoma kinase-rearranged anaplastic thyroid carcinoma. Journal of Clinical Oncology 201533 e84-e87. (doi:10.1200/JCO.2013.49.6596)

Received 5 July 2016

Revised version received 29 August 2016

Accepted 5 September 2016 